\title{
Intercropping Different Density of Galinsoga parviflora Can Increase Cadmium Accumulation in Radish
}

\author{
Qianqian Ma ${ }^{1, a}$, Xuena Yu ${ }^{1, b}$, Lijin Lin ${ }^{2, \mathrm{c}}$, and Ming'an Liao ${ }^{1, \mathrm{~d}^{\star}}$ \\ ${ }^{1}$ College of Horticulture, Sichuan Agricultural University, Chengdu, Sichuan, China \\ ${ }^{2}$ Institute of Pomology and Olericulture, Sichuan Agricultural University, Chengdu, Sichuan, China \\ a2282583901@qq.com, b1254967685@qq.com, 'Pll800924@163.com, 'Iman@sicau.edu.cn \\ ${ }^{*}$ Corresponding author
}

\begin{abstract}
Keywords: Intercropping; Density; Cadmium accumulation; Galinsoga parviflora; Radish
Abstract: A pot experiment was conducted to study the effects of intercropping density different density (1, 2, 3, 4 and 5) of cadmium (Cd) hyperaccumulator Galinsoga parviflora on $\mathrm{Cd}$ accumulation of radish. Intercropping different densities with G. parviflora decreased the growth of radish, and increased cadmium content in radish. After intercropping with G. parviflora, the $\mathrm{Cd}$ content in radish increased when the density of $G$. parviflora was not more than 3, and decreased when the density of $G$. parviflora was higher than 3 . When the density was not more than 3 , intercropping with radish increased biomass of $G$. parviflora, and decreased when the density was higher than 3 . Intercropping with radish increased $\mathrm{Cd}$ content in G. parviflora. With the increase of density, the $\mathrm{Cd}$ exaction by roots of $G$. parviflora increased when the density was not more than 4, and decreased when the density was higher than 4 . Therefore, in the Cd-contaminated soil, intercropping with $G$. parviflora could not be suitable for radish production.
\end{abstract}

\section{Introduction}

With the development of industrial and agricultural, the heavy metal concentration in soil increases, and the soil is contaminated more seriously [1]. When the heavy metal absorbs by plant and accumulates in plant body, and then accumulates in human body through the food chain, which threats the health of human [2]. The cadmium $(\mathrm{Cd})$ is one of the most toxic heavy metals with strong toxic to biology, especially to vegetable, and the vegetable is the indispensable part of human diet [3]. In agricultural production, reasonable intercropping can be used to improve the effective utilization of soil nutrients, water and light resources [4], and the appropriate planting density has been considered as one of the key factors to improve the yield and quality of vegetables [5]. When the roots of two species contacting, the root exudates may affect the soil heavy metal ions to increase or decrease the absorption of heavy metal ions by plant [6]. The zinc hyperaccumulator plant Sedum alfredii intercropping with maize, the heavy metal accumulation in grain of maize reduces significantly compared with monoculture [7]. The other studies shows that Cd hyperaccumulator plant Thlaspi caerulescens intercropping with Brassica pekinensis does not increase the $\mathrm{Cd}$ content in $\mathrm{B}$. pekinensis [8]. Galinsoga parviflora is a Cd hyperaccumulator [9], and radish is an important common vegetable. To decrease the $\mathrm{Cd}$ content in radish, the effects of intercropping different density of Cd-hyperaccumulator $G$. parviflora on Cd accumulation of radish were investigated in this study. The aim of the study was to screen intercropping density of $G$. parviflora which could decrease Cd content in radish, and provide a reference for other vegetables.

\section{Materials and Method}

Materials. The inceptisol soil samples were collected from Ya'an campus farm of Sichuan Agricultural University $\left(29^{\circ} 59^{\prime} \mathrm{N}, 102^{\circ} 59^{\prime} \mathrm{E}\right)$, China, in March 2014 . The basic properties of the soil were the same as reference [9]. G. parviflora seedlings with two pairs of euphyllas were collected from the Ya'an campus farm (from uncontaminated soil) in April 2014. 
Experimental Design. The experiment was conducted at the Ya'an campus farm from March to May in 2014. The soil samples were air-dried and passed through a 5-mm sieve. Three kilograms of the air-dried soil was weighed into each polyethylene pot $(15 \mathrm{~cm}$ high, $18 \mathrm{~cm}$ in diameter). Cd was added to soils as $\mathrm{CdCl}_{2} \cdot 2.5 \mathrm{H}_{2} \mathrm{O}$ at $10 \mathrm{mg} / \mathrm{kg}$. The soils were mixed immediately and again after 4 weeks, during which soil moisture was kept at $80 \%$. Two uniform seedlings of radish with one euphylla and corresponding density of $G$. parviflora seedling were transplanted into each pot. The density was 0 (monoculture), 1, 2, 3, 4 and 5 seedlings of $G$. parviflora, and each treatment was replicated three times using a completely randomized design with $10-\mathrm{cm}$ spacing between pots. The soil moisture content was maintained at $80 \%$ of field capacity from the time the plants were transplanted into the pots until the time the plants were harvested.

Sample Analysis. One month (after 30 d) later, the plants were gently removed from the soil. The roots and shoots of $G$. parviflora and radish were harvested and washed with tap water. The roots were immersed in $10 \mathrm{mM} / \mathrm{L} \mathrm{HCl}$ for $10 \mathrm{~min}$ to remove $\mathrm{Cd}$ adhering to the root surface. Then, the treatments and analyses of plants were described as in reference [9].

Statistical Analyses. Statistical analyses were performed using SPSS 13.0 statistical software (IBM, Chicago, IL, USA). Data were analyzed by one-way analysis of variance with least significant difference at a $5 \%$ confidence level.

\section{Results and Discussion}

Biomass of Radish. With the density increasing of G. parviflora, the root, tuberous root, leaf, edible part and whole plant biomasses of radish decreased (Table 1). The biomass of radish was ranked as: radish (monoculture) > radish (intercropping with $1 G$. parviflora) > radish (intercropping with $2 G$. parviflora) > radish (intercropping with $3 \mathrm{G}$. parviflora) > radish (intercropping with $4 G$. parviflora) $>$ radish (intercropping with $5 \mathrm{G}$. parviflora). When intercropping with 1, 2, 3, 4 and $5 \mathrm{G}$. parviflora seedlings, the root biomass of radish decreased by $4.55 \%(p>0.05), 13.46 \%(p>0.05)$, $27.27 \%(p<0.05), 50.00 \%(p<0.05)$ and $72.73 \%(p<0.05)$ respectively compared with monoculture, and the edible part biomass of radish decreased by $3.76 \%(p>0.05), 17.62 \%(p>0.05), 46.12 \%(p<$ $0.05), 50.51 \%(p<0.05)$ and $77.37 \%(p<0.05)$ respectively compared with monoculture, and the whole plant biomass of radish decreased by $3.77 \%(p>0.05), 17.55 \%(p>0.05), 45.80 \%(p<0.05)$, $50.50 \%(p<0.05)$ and $77.29 \%(p<0.05)$ respectively compared with monoculture. Therefore, intercropping with $G$. parviflora inhibited radish growth, which was not suitable for enhancing the yield of radish.

Table 1 Effects of intercropping density with G. parviflora on biomass of radish

\begin{tabular}{|l|l|l|l|l|l|}
\hline \multicolumn{1}{|c|}{ Treatments } & \multicolumn{1}{|c|}{$\begin{array}{c}\text { Root } \\
\text { (g/plant) }\end{array}$} & $\begin{array}{c}\text { Tuberous root } \\
\text { (g/plant) }\end{array}$ & $\begin{array}{c}\text { Leaf } \\
\text { (g/plant) }\end{array}$ & $\begin{array}{c}\text { Edible part } \\
\text { (g/plant) }\end{array}$ & $\begin{array}{c}\text { Whole plant } \\
\text { (g/plant) }\end{array}$ \\
\hline Radish (monoculture) & $0.22 \pm 0.02 \mathrm{a}$ & $5.43 \pm 0.13 \mathrm{a}$ & $7.34 \pm 0.22 \mathrm{a}$ & $12.77 \pm 0.35 \mathrm{a}$ & $12.99 \pm 0.37 \mathrm{a}$ \\
\hline Radish (1 G. parviflora) & $0.21 \pm 0.03 \mathrm{a}$ & $5.39 \pm 0.03 \mathrm{a}$ & $6.90 \pm 0.14 \mathrm{ab}$ & $12.29 \pm 0.17 \mathrm{a}$ & $12.50 \pm 0.19 \mathrm{a}$ \\
\hline Radish (2 G. parviflora) & $0.19 \pm 0.02 \mathrm{ab}$ & $4.45 \pm 0.07 \mathrm{~b}$ & $6.07 \pm 0.64 \mathrm{~b}$ & $10.52 \pm 0.71 \mathrm{~b}$ & $10.71 \pm 0.73 \mathrm{~b}$ \\
\hline Radish (3 G. parviflora) & $0.16 \pm 0.02 \mathrm{~b}$ & $1.94 \pm 0.09 \mathrm{c}$ & $4.94 \pm 0.26 \mathrm{c}$ & $6.88 \pm 0.34 \mathrm{c}$ & $7.04 \pm 0.36 \mathrm{c}$ \\
\hline Radish (4 G. parviflora) & $0.11 \pm 0.03 \mathrm{c}$ & $1.48 \pm 0.06 \mathrm{~d}$ & $4.84 \pm 0.10 \mathrm{c}$ & $6.32 \pm 0.16 \mathrm{c}$ & $6.43 \pm 0.17 \mathrm{c}$ \\
\hline Radish (5 G. parviflora) & $0.06 \pm 0.01 \mathrm{~d}$ & $0.76 \pm 0.03 \mathrm{e}$ & $2.13 \pm 0.52 \mathrm{~d}$ & $2.89 \pm 0.55 \mathrm{~d}$ & $2.95 \pm 0.56 \mathrm{~d}$ \\
\hline
\end{tabular}

Cd Content in Radish. After intercropping with G. parviflora, the Cd contents in root, tuberous root, leaf, edible part and whole plant of radish increased when the density of G. parviflora was not more than 3, and decreased when the density of G. parviflora was higher than 3 (Table 2), which was consistent with other studies [10]. The Cd contents in root, tuberous root, leaf, edible part and whole plant of radish was ranked as: radish (intercropping with $3 \mathrm{G}$. parviflora) > radish (intercropping with $4 \mathrm{G}$. parviflora) > radish (intercropping with $5 \mathrm{G}$. parviflora) > radish (intercropping with $2 G$. parviflora) $>$ radish (intercropping with $1 \mathrm{G}$. parviflora) $>$ radish (monoculture). When intercropping with 1, 2, 3, 4 and 5 G. parviflora seedlings, the Cd content in root of radish increased by $149.61 \%(p$ 
$<0.05), 331.25 \%(p<0.05), 675.78 \%(p<0.05), 512.50 \%(p<0.05)$ and $334.38 \%(p<0.05)$ respectively compared with monoculture, and the Cd content in edible part of radish increased by $68.96 \%(p<0.05), 82.71 \%(p<0.05), 350.42 \%(p<0.05), 202.08 \%(p<0.05)$ and $176.46 \%(p<$ $0.05)$ respectively compared with monoculture, and the $\mathrm{Cd}$ content in whole plant biomass of radish increased by $69.75 \%(p<0.05), 85.08 \%(p<0.05), 353.36 \%(p<0.05), 205.04 \%(p<0.05)$ and $177.94 \%(p<0.05)$ respectively compared with monoculture. So, intercropping with $G$. parviflora could increase $\mathrm{Cd}$ content in radish, Therefore, in the Cd contamination farmland, intercropping with $G$. parviflora to reduce $\mathrm{Cd}$ content in radish should be carefully considered.

Table 2 Effects of intercropping density with G. parviflora on Cd accumulation of radish

\begin{tabular}{|l|c|c|c|c|c|}
\hline \multicolumn{1}{|c|}{ Treatments } & $\begin{array}{c}\text { Root } \\
(\mathrm{mg} / \mathrm{kg})\end{array}$ & $\begin{array}{c}\text { Tuberous root } \\
(\mathrm{mg} / \mathrm{kg})\end{array}$ & $\begin{array}{c}\text { Leaf } \\
(\mathrm{mg} / \mathrm{kg})\end{array}$ & $\begin{array}{c}\text { Edible part } \\
(\mathrm{mg} / \mathrm{kg})\end{array}$ & $\begin{array}{c}\text { Whole plant } \\
(\mathrm{mg} / \mathrm{kg})\end{array}$ \\
\hline Radish (monoculture) & $2.56 \pm 0.25 \mathrm{e}$ & $2.88 \pm 0.11 \mathrm{e}$ & $6.22 \pm 0.31 \mathrm{~d}$ & $4.80 \pm 0.22 \mathrm{~d}$ & $4.76 \pm 0.23 \mathrm{~d}$ \\
\hline Radish (1 G. parviflora) & $6.39 \pm 0.55 \mathrm{~d}$ & $3.86 \pm 0.34 \mathrm{~d}$ & $11.43 \pm 0.96 \mathrm{c}$ & $8.11 \pm 0.66 \mathrm{c}$ & $8.08 \pm 0.66 \mathrm{c}$ \\
\hline Radish (2 G. parviflora) & $11.04 \pm 1.30 \mathrm{c}$ & $4.66 \pm 0.23 \mathrm{c}$ & $11.79 \pm 1.26 \mathrm{c}$ & $8.77 \pm 0.67 \mathrm{c}$ & $8.81 \pm 0.68 \mathrm{c}$ \\
\hline Radish (3 G. parviflora) & $19.86 \pm 1.84 \mathrm{a}$ & $8.72 \pm 0.31 \mathrm{a}$ & $26.69 \pm 2.39 \mathrm{a}$ & $21.62 \pm 1.78 \mathrm{a}$ & $21.58 \pm 1.78 \mathrm{a}$ \\
\hline Radish (4 G. parviflora) & $15.68 \pm 0.96 \mathrm{~b}$ & $5.85 \pm 0.20 \mathrm{~b}$ & $17.14 \pm 0.79 \mathrm{~b}$ & $14.50 \pm 0.68 \mathrm{~b}$ & $14.52 \pm 0.69 \mathrm{~b}$ \\
\hline Radish (5 G. parviflora) & $11.12 \pm 0.33 \mathrm{c}$ & $4.98 \pm 0.12 \mathrm{c}$ & $16.23 \pm 1.30 \mathrm{~b}$ & $13.27 \pm 0.51 \mathrm{~b}$ & $13.23 \pm 0.51 \mathrm{~b}$ \\
\hline
\end{tabular}

Cd Accumulation of $G$. parviflora. After intercropping with radish, with the density increasing, the root and shoot biomasses of $G$. parviflora increased when the density was not more than 3 , and decreased when the density was higher than 3 (Table 3). Compared with 1 G. parviflora, the shoot biomasses of 2, 3 and 4 G. parviflora increased by $12.50 \%(p>0.05), 29.64 \%(p<0.05)$ and $8.93 \%$ $(p>0.05)$ respectively, and 5 G. parviflora decreased by $2.14 \%(p>0.05)$. The biomass of $G$. parviflora was ranked as: 3 G. parviflora $>2$ G. parviflora $>4$ G. parviflora $>1$ G. parviflora $>5$ G. parviflora. The Cd contents in roots and shoots of $G$. parviflora increased with the density increase of G. Parviflora (Table 3). The Cd content in G. parviflora was ranked as: 5 G. parviflora $>4 G$. parviflora $>3$ G. parviflora $>2$ G. parviflora $>1$ G. parviflora. The number of G. parviflora greater in unit area, the more $\mathrm{Cd}$ was absorbed, which is consistent with other studies [11-12]. Compared with 1 G. parviflora, the Cd content in shoots of 2, 3, 4 and 5 G. parviflora increased by $5.49 \%(p>0.05)$, $13.31 \%(p>0.05), 28.72 \%(p<0.05)$ and $37.22 \%(p<0.05)$ respectively. With the increase of density, the $\mathrm{Cd}$ exaction by roots of $G$. parviflora increased when the density was not more than 4 , and decreased when the density was higher than 4 (Table 3). The Cd exaction by shoots of G. parviflora increased when the density was not more than 3, and decreased when the density was higher than 3 . The Cd exaction by roots of $G$. parviflora was ranked as: 4 G. parviflora $>3$ G. parviflora $>5 G$. parviflora $>2$ G. parviflora $>1$ G. parviflora, and the Cd exaction by shoots of G. parviflora was $3 G$. parviflora $>4$ G. parviflora $>5$ G. parviflora $>2$ G. parviflora $>1$ G. parviflora. Compared with $1 G$. parviflora, the Cd extraction by shoots of 2, 3, 4 and 5 G. parviflora increased by $18.69 \%$ ( $p<0.05)$, $46.91 \%(p<0.05), 40.21 \%(p<0.05)$ and $34.29 \%(p<0.05)$ respectively.

Table 3 Effects of intercropping density with radish on Cd accumulation of G. parviflora

\begin{tabular}{|c|l|l|l|l|l|c|}
\hline \multirow{2}{*}{ Treatments } & \multicolumn{2}{|c|}{ Biomass (g/plant) } & \multicolumn{2}{c|}{ Cd content $(\mathrm{mg} / \mathrm{kg})$} & \multicolumn{2}{c|}{ Cd extraction $(\mu \mathrm{g} / \mathrm{plant})$} \\
\cline { 2 - 7 } & Roots & \multicolumn{1}{|c|}{ Shoots } & Roots & \multicolumn{1}{c|}{ Shoots } & Roots & Shoots \\
\hline 1 G. parviflora & $0.93 \pm 0.01 \mathrm{a}$ & $2.80 \pm 0.10 \mathrm{~b}$ & $16.44 \pm 0.62 \mathrm{c}$ & $20.58 \pm 0.82 \mathrm{c}$ & $15.34 \pm 0.42 \mathrm{~d}$ & $57.62 \pm 0.26 \mathrm{~d}$ \\
\hline 2 G. parviflora & $0.95 \pm 0.02 \mathrm{a}$ & $3.15 \pm 0.14 \mathrm{ab}$ & $16.81 \pm 0.44 \mathrm{bc}$ & $21.71 \pm 1.00 \mathrm{bc}$ & $15.97 \pm 0.06 \mathrm{~d}$ & $68.39 \pm 0.09 \mathrm{c}$ \\
\hline 3 G. parviflora & $0.98 \pm 0.01 \mathrm{a}$ & $3.63 \pm 0.17 \mathrm{a}$ & $18.65 \pm 0.64 \mathrm{~b}$ & $23.32 \pm 1.08 \mathrm{abc}$ & $18.28 \pm 0.36 \mathrm{~b}$ & $84.65 \pm 0.06 \mathrm{a}$ \\
\hline 4 G. parviflora & $0.94 \pm 0.01 \mathrm{a}$ & $3.05 \pm 0.35 \mathrm{~b}$ & $20.66 \pm 0.93 \mathrm{a}$ & $26.49 \pm 3.44 \mathrm{ab}$ & $19.46 \pm 0.64 \mathrm{a}$ & $80.79 \pm 1.12 \mathrm{~b}$ \\
\hline 5 G. parviflora & $0.80 \pm 0.04 \mathrm{~b}$ & $2.74 \pm 0.09 \mathrm{~b}$ & $21.59 \pm 0.99 \mathrm{a}$ & $28.24 \pm 1.75 \mathrm{a}$ & $17.27 \pm 0.03 \mathrm{c}$ & $77.38 \pm 2.41 \mathrm{~b}$ \\
\hline
\end{tabular}




\section{Conclusions}

Intercropping different density with Galinsoga parviflora decreased the growth of radish. After intercropping with $G$. parviflora, the Cd content in radish increased when the density of G. parviflora was not more than 3, and decreased when the density of G. parviflora was higher than 3 . The Cd content in radish was ranked as: radish (intercropping with $3 \mathrm{G}$. parviflora) > radish (intercropping with $4 \mathrm{G}$. parviflora) > radish (intercropping with $5 \mathrm{G}$. parviflora) $>$ radish (intercropping with $2 G$. parviflora) $>$ radish (intercropping with $1 \mathrm{G}$. parviflora) $>$ radish (monoculture). When the density was not more than 3, intercropping with radish increased biomass of $G$. parviflora, and decreased when the density was higher than 3. Intercropping with radish increased $\mathrm{Cd}$ content in G. parviflora. With the increase of density, the Cd exaction by roots of $G$. parviflora increased when the density was not more than 4, and decreased when the density was higher than 4 . Therefore, in the Cd-contaminated soil, intercropping with $G$. parviflora was not suitable for radish production.

\section{References}

[1] O.N. Belyaeva, R.J. Haynes, O.A. Birukova, Barley yield and soil microbial and enzyme activities as affected by contamination of two soils with lead, zinc or copper, Biology and Fertility of Soils 41 (2005) 85-94.

[2] S. Chowdhury, N. Bala, P. Dhauria, Bioremediation-a natural way for cleaner environment, International Journal of Pharmaceutical, Chemical and Biological Sciences, 2 (2012) 600-611.

[3] J.L. Yang, L.W. Liu, Y.Q. Gong, L.L. He, F. Wang, B. Wu, L.Z. Wang, Genotypic difference of cadmium accumulation in radish under cadmium stress, Proceedings of the Two Symposium on the Ten Session of the Chinese Horticultural Society 2007 (In Chinese).

[4] C. Li, X. He, S. Zhu, H. Zhou, Y. Wang, Y. Li, J. Yang, J. Fan, J. Yang, G. Wang, Y. Long, J. Xu, Y. Tang, G. Zhao, J. Yang, L. Liu, Y. Sun, Y. Xie, H. Wang, Y. Zhu, Crop diversity for yield increase, PLoS ONE 4 (2009) e8049.

[5] L.J. Liu, H.Q. Chen, X.B. Dai, H. Hui, D.X. Peng, Effect of planting density and fertilizer application on fiber yield of ramie (Boehmeria nivea), Journal of Integrative Agriculture 11 (2012) 1199-1206.

[6] C.L. Luo, Z.G. Shen, X.D. Li, Root exudates increase metal accumulation in mixed cultures: implications for naturally enhanced phytoextraction, Water, Air, and Soil Pollution 193 (2008) 147-154.

[7] X.M. Liu, Q.T. Wu, M. K. Banks, Effect of simultaneous establishment of Sedum alfredii and Zea mays on heavy metal accumulation in plants, International Journal of Phytoremediation 7 (2005) 43-53.

[8] J. Ingwersen, B. Bucherl, G. Neumann, T. Stremonoculture, Cadmium leaching from micro-lysimeters planted with the hyperaccumulator Thlaspi caerulescens: experimental findings and modeling, Journal of Environmental Quality, 35 (2006) 2055-2065.

[9] L.J. Lin, Q. Jin, Y.J. Liu, B. Ning, M.A. Liao, L. Luo, Screening of a new cadmium hyperaccumulator, Galinsoga parviflora, from winter farmland weeds using the artificially high soil cadmium concentration method, Environmental Toxicology and Chemistry 33 (2014) $2422-2428$.

[10] L.J. Lin, Q.H. Liu, J. Shi, M.A. Liao, L.Y. Mei, Intercropping different varieties of radish can increase cadmium accumulation in radish, Environmental Toxicology and Chemistry, 33 (2014) $1950-1955$.

[11] Y.X. Yang, X.M. Zhu, J.R. Shao, Z.B. Yang, P. Cheng, Influence of different mixed proportion on $\mathrm{Zn}$ and $\mathrm{Cd}$ enrichment of white clover and vetiver, Journal of Soil and Water Conservation 28 (2014) 266-275 (In Chinese).

[12] K.W. Huang, M.A. Liao, L.J. Lin, Effects of interplantation ratio of two ecotypes of Bidens pilosa on cadmium accumulation, Journal of Ecology and Rural Environment 31 (2015) 753-759 (In Chinese). 